\title{
Homeostasis of chosen microelements in liver of rats receiving lithium and/or selenium orally
}

\author{
Małgorzata Kiełczykowska', Ewelina Kopciał², Zbigniew Marzec², Irena Musik \\ ${ }^{1}$ Chair and Department of Medical Chemistry, Medical University of Lublin, Poland \\ ${ }^{2}$ Chair and Department of Bromatology, Medical University of Lublin, Poland \\ Kiełczykowska M, Kopciał E, Marzec Z, Musik I. Homeostasis of chosen microelements in liver of rats receiving lithium and/or selenium orally. \\ J Pre-Clin Clin Res. 2017; 11(2): 132-135. doi: 10.26444/jpccr/75707
}

\begin{abstract}
Introduction and objective. Lithium and selenium have been the subjects of extensive research for many years. Concern about the physiological action of these elements results from the application of lithium in medicine, as well as the beneficial influence of selenium supplementation in different pathological states. However, little data are available concerning their effect on the homeostasis of essential microelements in organs. Therefore, the aim of the current study was to evaluate the influence of lithium and/or selenium administration on homeostasis of iron, zinc, copper and manganese in the liver of rats.

Materials and method. The experiment was carried on 24 male Wistar rats (4 groups of 6 animals) subjected to the treatment with: group I (control) - saline; group II - lithium carbonate at a dose of $2.7 \mathrm{mg} \mathrm{Li} / \mathrm{kg} \mathrm{b.w.;} \mathrm{group} \mathrm{III} \mathrm{-} \mathrm{sodium} \mathrm{selenite} \mathrm{at} \mathrm{a} \mathrm{dose}$ of $0.5 \mathrm{mg} \mathrm{Se} / \mathrm{kg}$ b.w.; group IV - both lithium carbonate and sodium selenite at the doses mentioned above. Administration was performed for 6 weeks, once a day by stomach tube, in the form of water solutions.

Results. The tissue content of zinc, iron and manganese showed no statistical differences among the studied groups. Zn was slightly decreased in group III vs. control and group II. Fe was insignificantly enhanced in groups II and IV vs. control. Mn in group IV was slightly increased vs. groups II and III. Cu in group III was significantly decreased vs. group IV and slightly depleted vs. groups I and II.

Conclusion. With the exception of Cu in the Se-treated group, lithium and/or selenium did not affect the studied microelements' liver homeostasis in a significant way. These results may contribute to the knowledge of essential microelements homeostasis in human organisms undergoing lithium therapy, and/or selenium supplementation.
\end{abstract}

\section{Key words}

lithium, selenium, iron, manganese, copper, zinc, male rats, liver

\section{INTRODUCTION}

Lithium and selenium, rated among trace bioelements, have been for some time the subjects of extensive scientific research, and concern about their physiological role is still growing. As regards lithium, the interest in this element results mainly from its application as a medicine. It still remains a first choice drug in bipolar disorders patients [1]. Additionally, the possibility of its application in cases of other pathological states has been considered, e.g.: in therapy of neurodegenerative disorders or in preventing nephrolithiasis $[1,2]$. However, lithium therapy may be accompanied by side effects, affecting in an adverse way compliance as well as the life conditions of patients. The side effects of lithium therapy may include tremor, cognitive impairment, gastrointestinal, renal, parathyroid and thyroid disorders, as well as weight gain $[3,4]$.

Selenium has been revealed to play a complex role in the organism. Its antioxidant properties, being the consequence of its occurrance in antioxidant enzymes, make this the most important aspect of its physiological functions [5, $6,7]$. Selenium supplementation has shown a protective action against toxic agents [7], although it is necessary to take proper precautions to avoid overdosing. On the other

Address for correspondence: Małgorzata Kiełczykowska, Medical University of Lublin, Chodźki 4 a, 20-093 Lublin, Poland

E-mail: malgorzata.kielczykowska@umlub.pl

Received: 7 June 2017; accepted: 5 July 2017 hand, its deficiency may result in various disturbances of the organism [8]. The issue of both lithium therapy and selenium supplementation is not a straightforward problem, since these elements show a narrow therapeutic range $[9,10]$. As there is a lack of studies in available data concerning the influence of selenium or lithium on homeostasis of essential microelements, the current study was performed with the aim of contributing to the knowledge of this question. Additionally: 1) selenium has already been revealed to show protective action against side effects of some drugs [11]; 2) the search for protective agents against lithium toxicity has been already performed and some antioxidants have been found to be effective $[9,12]$. Previous studies by the authors have shown that selenium application could change the effects of lithium on bioelements homeostasis in the organism [13]. Therefore, the research was extended to study the effect of simultaneous treatment with selenium and lithium on chosen microelements homeostasis.

\section{OBJECTIVE}

The current study was performed with the aim of evaluating the influence of lithium and/or selenium administration on homeostasis of zinc, copper, manganese and iron in liver of rats. 


\section{MATERIALS AND METHOD}

The study was carried out on 24 adolescent male Wistar rats (130-160 g body weight) divided into 4 groups. During the experiment, the rats had free access to drinking water and standard feed LSM (AGROPOL S.J., Motycz, Poland) with no lithium and selenium supplementation. The composition of the diet is presented in Table 1.

Table 1. Composition of Standard Feed LSM

\begin{tabular}{lcc}
\hline Substance & Unit & Content \\
\hline Protein min. & {$[\%]$} & 16.00 \\
\hline Raw fats min. & {$[\%]$} & 2.80 \\
\hline Raw ash max. & {$[\%]$} & 7.00 \\
\hline Raw fibre max. & {$[\%]$} & 5.00 \\
\hline L-Lysine min. & {$[\%]$} & 0.80 \\
\hline DL-Methionine min. & {$[\%]$} & 0.50 \\
\hline Calcium min. & {$[\%]$} & 1.10 \\
\hline Phosphorus min. & {$[\%]$} & 0.60 \\
\hline Sodium max. & {$[\%]$} & 0.20 \\
\hline Vitamin A (retinol) E 672 & {$[j \mathrm{jm} / \mathrm{kg}]$} & 10,000 \\
\hline Vitamin D3 E 671 & {$[\mathrm{jm} / \mathrm{kg}]$} & 1,500 \\
\hline Vitamin E (alpha-tocopherol 50\%) & {$[\mathrm{mg} / \mathrm{kg}]$} & 25 \\
\hline Copper (copper sulphate 24.5\%) E 4 & {$[\mathrm{mg} / \mathrm{kg}]$} & 5 \\
\hline
\end{tabular}

The experiment was performed according to statutory bioethical standards and approved by I Local Ethical Commission of the Medical University in Lublin, Poland (Acceptance No.1 / 2013).

After 3 days of acclimatization, the rats were divided randomly into 4 groups (6 animals each): group I (control group) - given saline; group II - given a water solution of lithium carbonate at a dose of $2.7 \mathrm{mg} \mathrm{Li} / \mathrm{kg}$ b.w.; group III given a water solution of sodium selenite at a dose of $0.5 \mathrm{mg}$ $\mathrm{Se} / \mathrm{kg}$ b.w.; group IV given a water solution of both lithium carbonate and sodium selenite at doses of $2.7 \mathrm{mg} \mathrm{Li} / \mathrm{kg}$ b.w. and of $0.5 \mathrm{mg} \mathrm{Se} / \mathrm{kg}$ b.w. The administration was performed once a day by stomach tube, for a period of 6 weeks.

Each animal was weighed every day before treatment, and, based on the obtained body mass values, the appropriate amounts of the used solutions were calculated. At the conclusion of the study the rats were sacrificed under thiopental narcosis and samples of liver collected.

Aliquots of $4 \mathrm{~g}$ of rat liver, placed in quartz crucibles, were dried at a temperature of $105^{\circ} \mathrm{C}$ and subsequently subjected to dry mineralisation; first over a gas burner and then in a muffle furnace at a temperature of $450{ }^{\circ} \mathrm{C}$. To accelerate the burning process, the ashes were sprinkled with a $15 \%$ water solution of nitric acid (Suprapur ${ }^{\oplus}$, Merck). Next, the ash was dissolved in $5 \mathrm{~cm}^{3}$ of a $10 \%$ water solution of hydrochloric acid (Suprapur ${ }^{\oplus}$, Merck). The content of the crucibles was then transferred quantitatively into measuring flasks and made up to the volume of $10 \mathrm{~cm}^{3}$ with deionised water. Next, the concentrations of copper, zinc, manganese and iron were determined in the obtained solutions. The assay was performed by using flame atomic absorption spectroscopy (FAAS) in an air-acetylene flame [14] with help of a SOLAAR M5 apparatus (Thermo Elemental Ltd.). The wavelengths were as follows: $\mathrm{Zn}-213.9 \mathrm{~nm}, \mathrm{Fe}-248.3 \mathrm{~nm}, \mathrm{Cu}-324.8 \mathrm{~nm}$,
$\mathrm{Mn}-279.5 \mathrm{~nm}$. The obtained results were expressed in $\mu \mathrm{g} \cdot \mathrm{g}^{-1}$ of wet tissue.

Statistical analysis was performed using STATISTICA program (version 10.0). Shapiro-Wilk test was used for verifying the normality of data distribution. In the case of normally distributed variables, a one-way analysis of variance (ANOVA), followed by Tukey test, was applied for analysis of the differences among the studied groups. For non-normally distributed variables Kruskal-Wallis one way analysis of variance was used. Values were considered significant with $\mathrm{p}<0.05$.

\section{RESULTS}

The tissue content of zinc did not show any statistical differences among the studied groups. However, in group III receiving selenium, a slight decrease vs. control ( $\mathrm{p}=0.275858)$ as well as vs. group II provided with lithium $(\mathrm{p}=0.076032)$, were observed.

Similarly, the comparison of liver content of iron in the studied groups revealed no statistical differences. However, an insignificant increase vs. control was observed in group II (lithium given animals; $\mathrm{p}=0.277834$ ) and in group IV (lithium + selenium given animals; $\mathrm{p}=0.282961$ ).

The obtained values of manganese content in liver in the studied groups did not markedly differ from one another. Statistical analysis, however, revealed the existence of some insignificant differences: liver $\mathrm{Mn}$ content in group IV (lithium + selenium given animals) was slightly increased vs. group II (lithium treatment; $\mathrm{p}=0.182222$ and group III (selenium treatment; $\mathrm{p}=0.196007$ ).

Copper was the only studied element which showed any statistically significant differences. Its liver content in group III (selenium treated rats) was significantly decreased compared to group IV (lithium + selenium treated animals; $\mathrm{p}=0.022242$ ). Additionally, a depletion compared to the remaining groups was observed, although in this case the differences were insignificant, with $\mathrm{p}=0.403623$ vs. group I (control) and $\mathrm{p}=0.347632 \mathrm{vs}$. group II (lithium administered).

All the presented results are collected in Fig. 1.

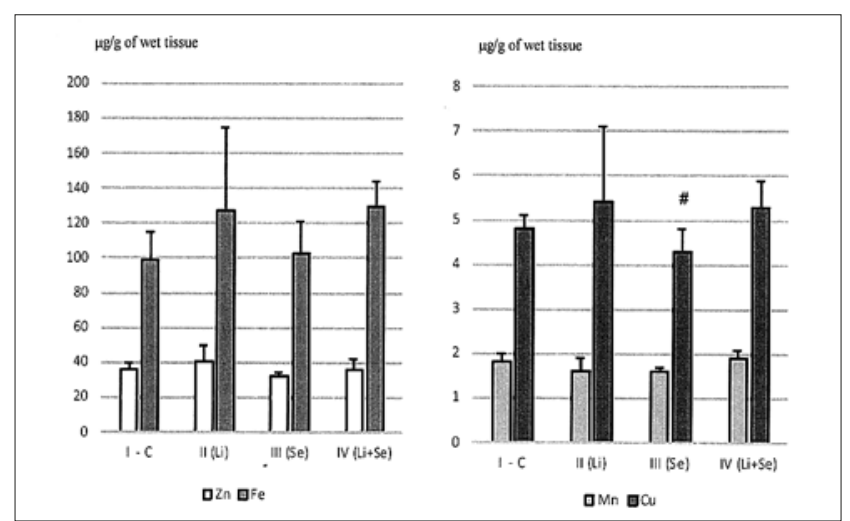

Figure 1. The content of the studied microelements in liver of rats receiving lithium and/or selenium. $\# p<0.05$ vs. group IV 


\section{DISCUSSION}

In the current study, none of the treatments used affected any studied element compared to control in a significant way, which seems to be very important in view of the detoxifying role of the liver. The significance of maintaining the homeostasis of essential microelements cannot be overrated, considering the participation of iron and copper in the development of diseases of this organ $[15,16]$, the role of manganese superoxide dismutase in liver tumour suppression [17], or the protective effect of zinc in the case of hepatoxicity of lithium [12]. Additionally, the necessity of maintaining the proper liver functions must be highlighted, considering that lithium therapy in psychiatric subjects is usually used for some years [4].

The results of the current study regarding changes observed in selenium-treated animals, are generally consistent with those obtained by other researchers. According to Sivrikaya et al., in rats intraperitoneally treated with sodium selenite no changes of liver iron and copper, accompanied by a significant zinc increase, was revealed. In animals subjected to an additional acute exercise, the outcomes were the same [6]. South et al. reported no well-marked effect of dietary selenium on liver iron. The use of diets with different selenium levels (adequate or deficient) caused no significant alterations of hepatic iron in mice [5]. According to Erkekogku et al., the application of diets with different selenium content (regular, supplemented or deficitient) resulted in no changes in hepatic zinc, copper, iron and manganese in rats [7].

The study performed by Al-Awadi et al. supplied further confirmation of rather slight relationships among selenium, zinc, copper as well as manganese in liver. The researchers studied alterations of these elements in rats administered some plant extracts. In liver, an increase in $\mathrm{Zn}, \mathrm{Cu}$ and $\mathrm{Mn}$, but no significant changes of Se were observed, while in plasma, enhanced selenium was concomitant with an increase in $\mathrm{Zn}, \mathrm{Cu}$ and $\mathrm{Mn}$ [18]. These differences regarding the plasma and liver elemental profile also confirm the usefulness of the animal model in scientific research, as in human studies blood is the only available material.

Monedero-Prieto et al. also reported no significant influence of additional selenium (in this case in organic form - selenomethionine) on zinc and manganese in rat liver. Furthermore, these authors revealed a slight tendency towards liver copper decrease in animals given selenium [19], which confirms the results of the current study. The negative relationship between selenium and copper is also supported by the study performed by Nwagha et al.; they found that in the serum of pregnant women throughout the duration of pregnancy $\left(1^{\text {st }}, 2^{\text {nd }}\right.$ and $3^{\text {rd }}$ trimester $)$, a selenium depletion was concomitant with an increase of copper [8].

However, some researchers have reported contradictory results. In rats fed with a diet containing normal selenium level (sodium selenite form), an increase in dietary copper content resulted in an enhancement of hepatic selenium [20]. With regard to iron, Matsumoto et al. studied the liver iron in selenium-deficient rats in comparison with normal selenium animals. The existence of statistical differences was revealed. In Se-deficient animals, hepatic iron was higher in the first period of the life of the animals (10-20 weeks). Surprisingly, after 50 weeks of life, in normal selenium rats a higher liver Fe was observed, although liver selenium in both groups did not change during all studies [21].
Previous studies by the authors of the current study revealed the influence of treatment with lithium carbonate on calcium [13]. The presented study was extended to investigate the effect of lithium on the essential microelements. Apart from their great importance for the organism, another reason for the extension was the latest reports which revealed disturbances of serum zinc, iron and selenium in bipolar disorder patients, compared to healthy control subjects [22].

The issue of the effect of lithium exposure on microelements' homeostasis has already been a subject of scientific research. The influence of lithium oral administration on copper homeostasis was reported by Chmielnicka and Nasiadek, who found an increase in urinary copper excretion in $\mathrm{Li}$ given rats [23].

In rats fed a diet with normal protein content supplemented with lithium, liver zinc and copper were significantly decreased, whereas iron and manganese remained unchanged. Interestingly, in animals fed with the Li-supplemented low protein diet, hepatic manganese was increased, whereas zinc, iron and copper remained unchanged [24]. In contrast, in a study performed by Dhawan et al. depression of iron as well as increase in zinc and copper in liver of rats undergoing dietary lithium administration was observed [25], although in both studies the period of the experiment, the administered dose and the way of exposure were the same. Since in these studies the microelements were much more disturbed than in the current experiment, the existence of any dependence of the obtained results on the gender and species of experimental animals seems possible, as both Tandon et al. and Dhawan et al. used female Sprague-Dawley rats, while the current study was performed on male Wistar rats.

In the current study, zinc was not affected by lithium exposure. This lack of hepatic zinc changes seems to be beneficial as lithium administration was reported to be applied in the case of psychiatric disturbances occurring in Wilson's disease [26]. In Wilson's disease, increased copper hepatic deposit occurs and zinc, known to be a copper antagonist preventing its absorption and liver accumulation, is used in the treatment of this disorder [27]. The findings concerning the protective properties of zinc against hepatotoxic effects of lithium [12] can be an additional reason for assuming that no alterations of hepatic zinc in lithium-treated animals is a fact of considerable importance.

\section{CONCLUSIONS}

The results of the current study suggest that selenium and lithium, administered both alone and simultaneously, did not cause significant changes of liver homeostasis of essential microelements. These results can contribute to the knowledge of the processes occurring in organisms undergoing lithium treatment or selenium supplementation. Additionally, they support the outcomes of previous studies by the authors which allow the suggestion that the possibility of selenium supplementation could be taken into account as a beneficial adjuvant in lithium therapy. 


\section{REFERENCES}

1.Dell'Osso L, Del Grande C, Gesi C, Carmassi C, Musetti L. A new look at an old drug: neuroprotective effects and therapeutic potentials of lithium salts. Neuropsychiatr Dis Treat. 2016; 12: 1687-1703.

2.Zhang X, Aggarwal P, Li X, Oakman C, Wang Z, Rodriguez R. The role of lithium carbonate and lithium citrate in regulating urinary citrate level and preventing nephrolithiasis. Int J Biomed Sci. 2009; 5(3): 215-222.

3. Gitlin M. Lithium side effects and toxicity: prevalence and management strategies. Int J Bipolar Disord. 2016; 4(1): 27.

4.Zyoud SH, Waring WS, Sweileh WM, Al-Jabi SW. Global Research Trends in Lithium Toxicity from 1913 to 2015: A Bibliometric Analysis Basic Clin Pharmacol Toxicol. 2017; http://onlinelibrary.wiley.com/ doi/10.1111/bcpt.12755/epdf

5. South PK, Morris VC, Smith AD, Levander OA. Effect of selenium deficiency on liver iron stores in mice. Nutr Res. 2000; 20(7): 1027-1040.

6. Sivrikaya A, Akil M, Bicer M, Kilic M, Baltaci AK, Mogulkoc R. The effect of selenium supplementation on elements distribution in liver of rats subject to strenuous swimming. Bratisl Lek Listy. 2013; 114(1): $12-14$.

7.Erkekoglu P, Arnaud J, Rachidi W, Kocer-Gumusel B, Favier A, Hincal F. The effects of di(2-ethylhexyl) phthalate and/or selenium on trace element levels in different organs of rats. J Trace Elem Med Biol. 2015; 29: 296-302

8. Nwagha UI, Ogbodo SO, Nwogu-Ikojo EE, Ibegbu DM, Ejezie FE, Nwagha TU, Dim CC. Copper and selenium status of healthy pregnant women in Enugu, southeastern Nigeria. Niger J Clin Pract. 2011; 14(4): $408-412$.

9. Vijaimohan K, Mallika J, Shyamala DC. Chemoprotective Effect of Sobatum against Lithium-Induced Oxidative Damage in Rats. J Young Pharm. 2010; 2(1): 68-73.

10. Wrobel JK, Power R, Toborek M. Biological activity of selenium: Revisited. IUBMB Life. 2016; 68(2): 97-105.

11. Doğan S, Yazici H, Yalçinkaya E, Erdoğdu HI, Tokgöz SA, Sarici F, Namuslu M, Sarikaya Y. Protective Effect of Selenium Against CisplatinInduced Ototoxicity in an Experimental Design. J Craniofac Surg. 2016; 27(7): e610-e614.

12. ChadhaVD, Bhalla P, Dhawan DK. Zinc modulates lithium-induced hepatotoxicity in rats. Liver Int. 2008; 28(4): 558-565.

13. Kiełczykowska M, Musik I, Kurzepa J, Żelazowska R, Lewandowska A, Paździor M, Kocot J. The Influence of Lithium and/or Selenium Treatment on Homeostasis of Chosen Bioelements in Rats. Biol Trace Elem Res. 2016; http://link.springer.com/article/10.1007\%2Fs12011016-0906-x
14. Herman K. An outline of atomic absorption spectrometry. Based on ANTI UNICAM - atomic absorption spectrometry methods manual. Warsaw, 1991

15. Milic S, Mikolasevic I, Orlic L, Devcic E, Starcevic-Cizmarevic N, Stimac D, Kapovic M, Ristic S. The Role of Iron and Iron Overload in Chronic Liver Disease. Med Sci Monit. 2016; 22: 2144-2151.

16. Morrell A, Tallino S, Yu L, Burkhead JL. The role of insufficient copper in lipid synthesis and fatty-liver disease. IUBMB Life. 2017; 69(4): 263-270.

17. Konzack A, Jakupovic M, Kubaichuk K, Görlach A, Dombrowski F, Miinalainen I, Sormunen R, Kietzmann T. Mitochondrial Dysfunction Due to Lack of Manganese Superoxide Dismutase Promotes Hepatocarcinogenesis. Antioxid Redox Signal. 2015; 23(14): 1059-75.

18. Al-Awadi FM, Anim JT, Srikumar TS, Mona Al-Rustom. Possible Role of Trace Elements in the Hypoglycemic Effect of Plants Extract in Diabetic Rats. J Trace Elem Exp Med. 2004; 17: 31-44.

19. Monedero-Prieto MJ, González-Pérez MJ, González-Reimers E, Hernández-Pérez O, Monereo-Muñoz M, Galindo-Martín L, QuinteroPlatt G, Abreu-González P. Effects of selenium on liver and muscle contents and urinary excretion of zinc, copper, iron and manganese. Biol Trace Elem Res. 2014; 158(2): 224-229.

20. Yu S, Beynen AC. The lowering effect of high copper intake on selenium retention in weanling rats depends on the selenium concentration of the diet. J Anim Physiol a Anim Nutr. 2001; 85: 29-37.

21. Matsumoto K, Terada S, Ariyoshi M, Okajo A, Hisamatsu A, Ui I, Endo K. The effect of long-running severe selenium-deficiency on the amount of iron and zinc in the organs of rats. Molecules. 2009; 14(11): 4440-4453.

22. Chowdhury MI, Hasan M, Islam MS, Sarwar MS, Amin MN, Uddin SM, Rahaman MZ, Banik S, Hussain MS, Yokota K, Hasnat A. Elevated serum MDA and depleted non-enzymatic antioxidants, macro-minerals and trace elements are associated with bipolar disorder. J Trace Elem Med Biol. 2017; 39: 162-168.

23. Chmielnicka J, Nasiadek M. The trace elements in response to lithium intoxication in renal failure. Ecotoxicol Environ Saf. 2003; 55(2): $178-183$.

24. Tandon A, Nagpaul JP, Bandhu H, Singh N, Dhawan DK. Effect of lithium on hepatic and serum elemental status under different dietary protein regimens. Biol Trace Elem Res. 1999; 68(1): 51-62.

25. Dhawan D, Singh A, Singh B, Bandhu HK, Chand B, Singh N. Effect of lithium augmentation on the trace elemental profile in diabetic rats. BioMetals. 1999; 12(4): 375-381.

26. Rich AM, Lajoie TM. Wilson's disease--treatment of psychiatric manifestations in pregnancy. Psychosomatics. 2012; 53(2): 175-177.

27. Zhao J, Shirley RB, Dibner JJ, Wedekind KJ, Yan F, Fisher P, Hampton TR, Evans JL, Vazquez-Añon M. Superior growth performance in broiler chicks fed chelated compared to inorganic zinc in presence of elevated dietary copper. J Anim Sci Biotechnol. 2016; 7: 13 